\title{
Failure to define low back pain as a disease or an episode renders research on causality unsuitable: results of a systematic review
}

\author{
Emad M. Ardakani ${ }^{1 *}$ (D), Charlotte Leboeuf-Yde ${ }^{1,2}$ and Bruce F. Walker ${ }^{1}$
}

\begin{abstract}
Background: Causative factors may be different for the very first onset of symptoms of the 'disease' of low back pain (LBP) than for ensuing episodes that occur after a pain-free period. This differentiation hinges on a life-time absence of low back pain at first onset and short-term absence for further episodes. In this systematic review, we explored whether researchers make these distinctions when investigating the causality of LBP.

Methods: A literature search of PUBMED, CINAHL, and SCOPUS databases was performed from January 2010 until September 2016 using the search terms 'low back pain' or 'back pain' and 'risk factor' or 'caus*' or 'predict*' or 'onset' or 'first-time' or 'inception' or 'incidence'. Two reviewers extracted information on study design, types of episodes of back pain to distinguish the disease of LBP and recurring episodes, and also to determine the definitions of disease- or pain-free periods.

Results: Thirty-three articles purporting to study causes of LBP were included. Upon scrutiny, 31 of the 33 articles were unclear as to what type of causality they were studying, that of the 'disease' or the episode, or a mere association with LBP. Only 9 studies used a prospective study design. Five studies appeared to investigate the onset of the disease of $L B P$, however, only one study truly captured the first incidence of LBP, which was the result of sports injury. Six appeared to study episodes but only one clearly related to the concept of episodes. Therefore, among those 11 studies, nine included both first-time LBP and episodes of LBP. Consequently, 22 studies related to the prevalence of LBP, as they probably included a mixture of first-time, recurring and ongoing episodes without distinction.

Conclusion: Recent literature concerning the causality of LBP does not differentiate between the 'disease' of LBP and its recurring episodes mainly due to a lack of a clear definition of absence of LBP at baseline. Therefore, current research is not capable of providing a valid answer on this topic.
\end{abstract}

Keywords: Low back pain, Cause, Risk factor, Onset, Incidence, Systematic review, Methodology

\section{Introduction}

\section{LBP in perspective}

Low back pain (LBP) is a common musculoskeletal condition in the general population and one of the five most common causes of disability worldwide [1]. It accounts for a considerable amount of healthcare visits and treatments, which places a great burden on health budgets in many countries [2]. Hence, it has been a condition of attention among various professions, consumers, and policy makers

\footnotetext{
* Correspondence: E.Ardakani@murdoch.edu.au

'School of Health Professions, Murdoch University, 90 South St, Murdoch, WA 6150, Australia

Full list of author information is available at the end of the article
}

in the healthcare sector. It is believed that most cases of LBP are non-specific [3, 4], in which no clear structural or anatomical cause can be identified.

Further, those with LBP at one point in time will have a strong tendency towards having continuing LBP or having it again, and those without LBP are unlikely to develop it [5].In fact, it has been shown to be a chronic disease [6-9], characterised by a stable pattern of episodes [5], which may occur frequently or rarely [10] and these episodes may be of short or of long duration [11, 12].

A search of the Cochrane library using the search term "low back pain" reveals many systematic reviews that conclude that no specific treatment has been found to 
be significantly superior in the management of nonspecific LBP than others, or indeed, even better than placebo [13-20], indicating a need to initiate a shift in the research direction from treatment to prevention.

\section{Concepts of risk factors, cause, and prevention}

A risk factor, as used in epidemiologic studies, is defined as "a factor that is causally related to a change in the risk of a relevant health process, outcome, or condition. The causal nature of the relationship is established on the basis of scientific evidence and causal inference." [21] This means that risk factors should be present prior to the onset of the disease in order to be considered causative. However the fact that one factor precedes another does not necessarily imply causality [22]. Causative factors must be avoidable or, at least, modifiable to make prevention possible.

If a suspected risk factor is found to occur concomitantly with a disease, it infers association and not causation, unless it is certain that the suspected risk factor was present before the disease onset. Therefore, in the case of mere associations, it is not known if the suspected risk factor is actually causal or only a so-called risk marker or risk indicator [21]. Hence, usually a prospective study design is required to be able to ascribe a 'cause' to a disease. Other tenets, in addition to associations and temporality, are needed to establish with some certainty the causal link between two variables, as so eloquently described by Bradford Hill [22].

\section{Prevention of chronic recurring diseases}

In the case of a chronic recurring illness, prevention can be aimed at either the onset of the disease or the onset of episodes. In back pain, there seems to be some confusion on this issue. Back pain is described by many not as a 'disease' but a 'symptom', and it is accurate to say that 'symptoms' are the manifestations of a 'disease', so these two concepts should be separated. This is of great importance because causative factors are possibly quite different for the disease itself than for its various episodes, when symptoms become apparent. Therefore, it is also reasonable to postulate that the preventive approach may be different for the disease than the episodes of symptoms.

\section{Comparison of LBP with asthma and migraine}

Asthma and migraine are both chronic recurrent diseases, characterised by episodes and often a total absence of symptoms in between. Both are likely to have a different set of causes for the disease of asthma and the disease of migraine as opposed to the subsequent symptoms (episodes). Thus, there would be an intrinsic reason why asthma and migraine are present, whereas external factors often trigger the onset of the symptoms/episodes.
It is possible that for back pain - also a chronic, recurrent disorder - the situation is the same. Therefore, some people have the disease of back pain, just like others have the disease of asthma. For those having an underlying predisposition to episodes of back pain or asthma attacks, it would be possible to identify factors that bring on these symptoms or episodes. In back pain, this could be awkward work positions, inactivity or sudden movements, whereas in asthma it could be exertion or exposure to smoke or cold air. If these triggering factors can be avoided, then it would be possible to reduce the number of episodes. Although episodes of both asthma and migraine can mostly be successfully treated and often also prevented, there is, as yet, no preventive approach known to be able to prevent these 'diseases', because the underlying predispositions for these asthmatic and $\mathrm{mi}$ graine episodes are unknown. Therefore, it is critical that research on causes of back pain, asthma, and migraine determines clearly whether to target the onset of the 'disease' (i.e. the underlying predisposition) or the symptoms (i.e. the episodes).

\section{Importance of the disease-free and episode-free periods}

To search for disease causation, truly 'disease-free' people should be followed over time to identify those who develop the disease, and the potential risk factors must be shown to be present before the disease commences. Recall bias and memory decay suggest it is not sufficient to ask study participants if they had pain in the last month or the last year and, if the answer is 'no', we cannot assume, as some authors appear to, that they never had the disease prior to that time. The study of the causes of the 'disease' of LBP requires access to people completely free of it, as this prevents contamination by those who were merely in a pain-free period between episodes of back pain. This is obviously not an easy task.

Similarly, an investigation into the causes of episodes requires that 'episode-free' people be studied over time. This necessitates a clear definition of both 'pain-free' and the length of this pain-free period.

Therefore, the definition of what constitutes the primary health problem in question and what can be considered to be an episode-free period prior to the start of the study must be clearly understood. That is, life-long absence of symptoms, in the case of the study of the 'disease', and absence of symptoms in between episodes, in the case of the study of the episodes. Otherwise, a mixture of these two concepts results in ambiguity, as it will mix causative factors for the 'disease' with the causative factors for its episodes. In conclusion, it is important to separate the search for causes of the 'disease' from the search for the causes of episodes. 


\section{Causal research disregards the concept of disease vs. episode}

It is often stated in the literature that causes of LBP are largely unknown, which probably means that the causes of the disease of LBP are unknown. Nevertheless, concerning LBP research, the search for causative factors seems to disregard the concept of the 'disease' vs. episode. A multitude of studies have been conducted over past decades on the topics of 'cause,' 'risk', and 'prevention', seemingly without a clear distinction of whether these studies related to the disease of LBP, its episodes, an undefined mixture of both, or perhaps even constant and long-lasting LBP without any remissions.

\section{Prospective design is not the same as temporality}

Some of these LBP studies seem to be carried out based on the concept that a prospective design guarantees that the statistical association between two variables is causative, disregarding the rule of prior absence of disease. Also some authors seem to ignore the concept of temporality (a fundamental causation tenet previously described by Bradford Hill [22]), but use the term 'risk factor' for variables that were found to be present at the same time as the disease under investigation. This is at odds with the principle of a causal relationship, as these factors can only be interpreted as a 'risk marker' or a potential 'risk indicator'. In other words, they could possibly be true causative agents, but the study design can only attribute their presence as a statistical association.

\section{Aims and objectives}

To alert the research community to these two concepts (disease vs. episode and risk factor vs. risk marker or indicator), we performed a systematic review of contemporary studies that purported to investigate the causes of LBP. Our overall aim was to see if a sample of recent studies on the causes of LBP differentiate between disease and episodes and if their approach makes it possible to draw a conclusion on causality for these specific outcomes. Our specific objectives were to:

1. Establish the proportion of included studies that used a prospective study design, which would usually be necessary in order to establish causality.

2. Determine whether included studies were concerned with the onset of the disease of LBP or the onset of episodes, or if they failed to identify the appropriate target group in this respect.

\section{Methods}

Search strategy, inclusion criteria, and exclusion criteria The PRISMA statement was used to assist the methods for the study. A literature search of PUBMED, CINAHL, and SCOPUS databases was performed for contemporary studies. We arbitrarily selected the period from January 2010 until September 2016. Articles containing the following keywords were included: (low back pain OR back pain) AND (risk factor OR caus* OR predict* OR onset OR first-time OR inception OR incidence). An additional citation search was performed on retrieved articles' reference lists.

The purpose of the literature search was to identify recent studies that investigated the potential causes of nonspecific LBP. The cause was considered the topic of the articles when words such as: risk factor, cause, predict were used in the title, abstract, or in the study objectives.

We did not intend to capture all existing literature on this topic; we were only interested in obtaining a fairly representative group of articles from the contemporary literature, in order to gain an understanding of the way researchers, in general, approached the topic under scrutiny. We included only full-text articles written in English.

Our exclusion criteria were: case reports, systematic reviews, study populations with specific LBP (where the pain can be assigned to a known specific pathology such as a disc herniation, spinal stenosis, infection, fracture, tumour, etc.), LBP with non-organic signs and symptoms, study populations seeking secondary/tertiary care, LBP studied in a special population (e.g. people with autism, Parkinson's disease or pregnant women), and studies investigating only chronic/persistent LBP. Regarding the exclusion of exclusive studies of chronic/persistent LBP, we believe it is possible that risk factors are different for this type of LBP. Importantly, we were interested to understand if researchers had implemented a clear definition of an episode of LBP (either the very first or a recurrent one). Therefore, the presence of a pain-free period was crucial in this regard. This phenomenon will not frequently happen in patients with chronic persistence LBP.

Throughout the selection process, it was decided to exclude case-control studies because of their retrospective approach [23-26] and those studies in which clinicians' views were sought [27] (Fig. 1).

\section{Article inclusion and selection process}

One reviewer (EA) conducted the database search and removed all duplicates. Two reviewers (EA and CLY) independently screened titles and abstracts to identify potentially eligible studies based on the selection criteria. Articles selected by either reviewer were included for the full-text assessment. The full-texts of all selected articles were then screened independently by the two reviewers for inclusion in the data extraction phase. Articles excluded by both reviewers were excluded from the review. Where any disagreement between the two reviewers occurred and could not be resolved via a 


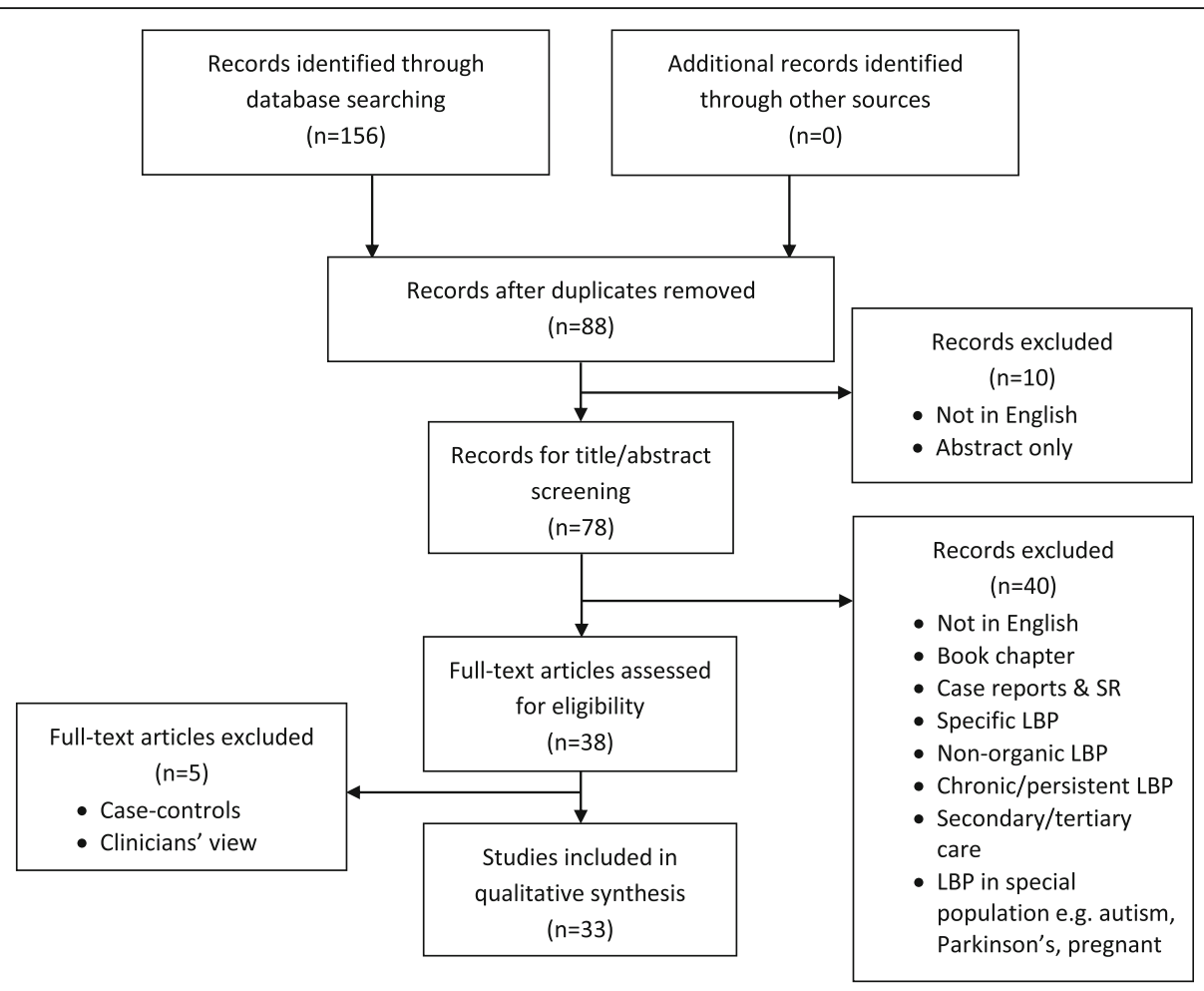

Fig. 1 Flow chart of search results

discussion and consensus approach, a third person/ author (BW), not involved in the selection process, would be asked to adjudicate.

\section{Data extraction}

A data extraction form (checklist) was developed for extracting relevant characteristics of included studies (Table 1). The rationale for these items is described below. The form was piloted by the reviewers using six articles, and some modifications were made to better suit the aims and objectives of the review. Both reviewers independently participated in data extraction and disagreements were resolved via discussion between the two reviewers. In the case of continued disagreement, the third author could be consulted.

\section{Rationale for choice of data extraction items}

Initially, the information mentioned in the title, objectives, and methods was taken into account. Information from the result section was taken into consideration only when there was uncertainty surrounding the methodology.

Because studying cause(s) and risk factor(s) of a disease mandates a certain type of study design, we extracted information on the individual study designs. Another important item considered was the various types of an episode of back pain and whether it was a first episode ever or a recurring one. Also, we looked for a definition of a non-episode which, in turn, would help us differentiate types of episodes. Finally, we were also interested if data collection regarding risk factors had been done prior to the onset of LBP. For descriptive purposes, the recall period for LBP episodes was also recorded.

\section{Results}

\section{Description of studies}

As shown in Fig. 1, of the initial 156 potential articles, 33 articles were included in this review [28-60]. A description of these articles is found in Table 1 and summarised below. Of the studies reported in these articles, 12 were conducted in Asia/Middle East, 13 related to European countries/North America, 3 were from respectively Australia and Africa, and 2 from South America.

The terms that alerted us to their suitability of inclusion in our study were: "risk factor(s)" $(N=29)$ [28-40, 42, 45-52, 54-60], "risk" $(\mathrm{N}=2)$ [41, 43], "predict" [44], "incidence" $(N=3)$ [35, 38, 58], "onset" $(\mathrm{N}=2)$ [38, 44]. Also, one study investigated "modifiable personal factors" [44], and another study reported "triggers" of an acute episode of LBP [53].

The majority of included studies utilised a crosssectional study design $(N=18,54 \%)$, whereas the number of studies using a prospective design was 9 (27\%). The other designs were found to be retrospective $(N=5)$ 


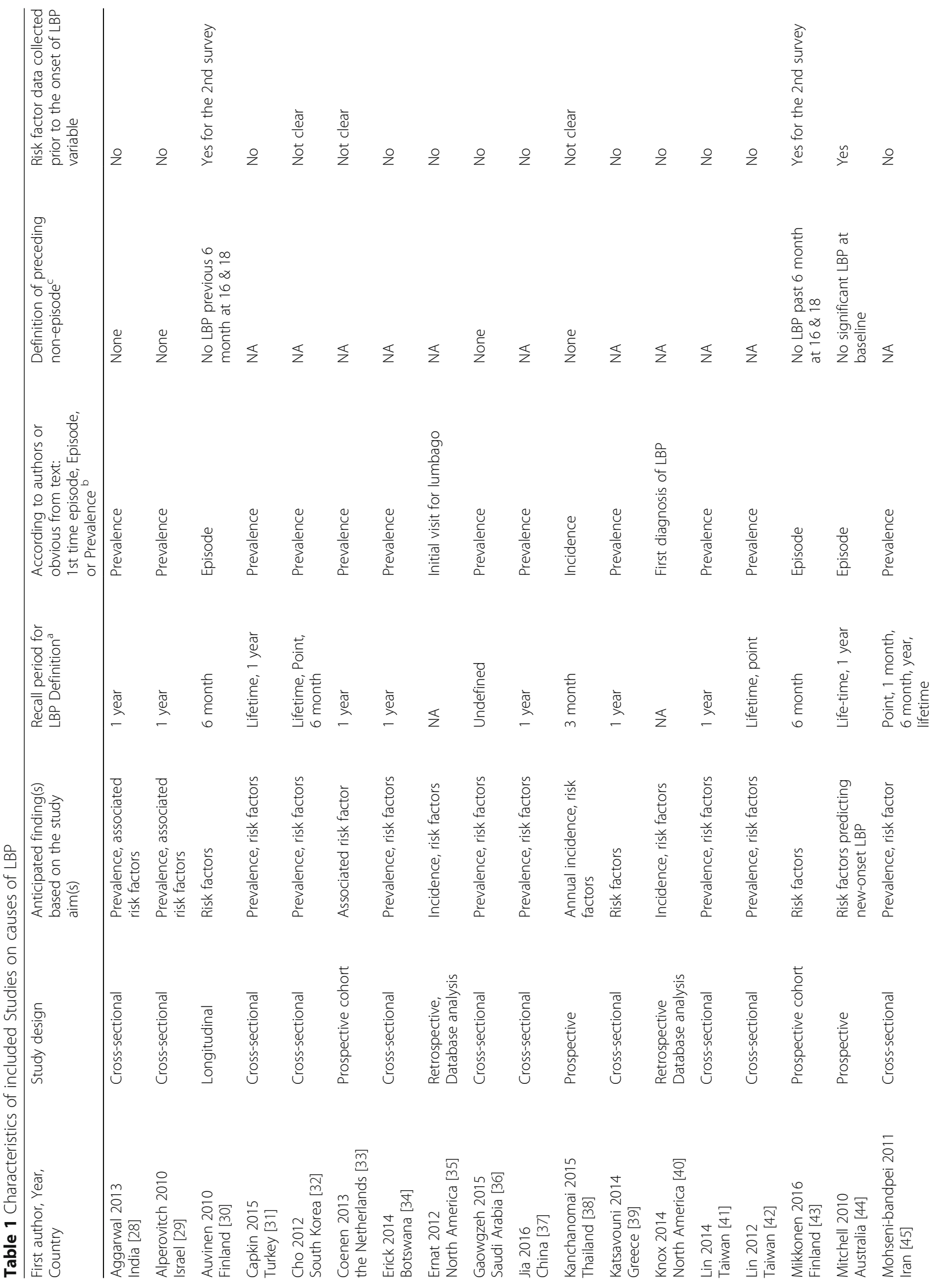




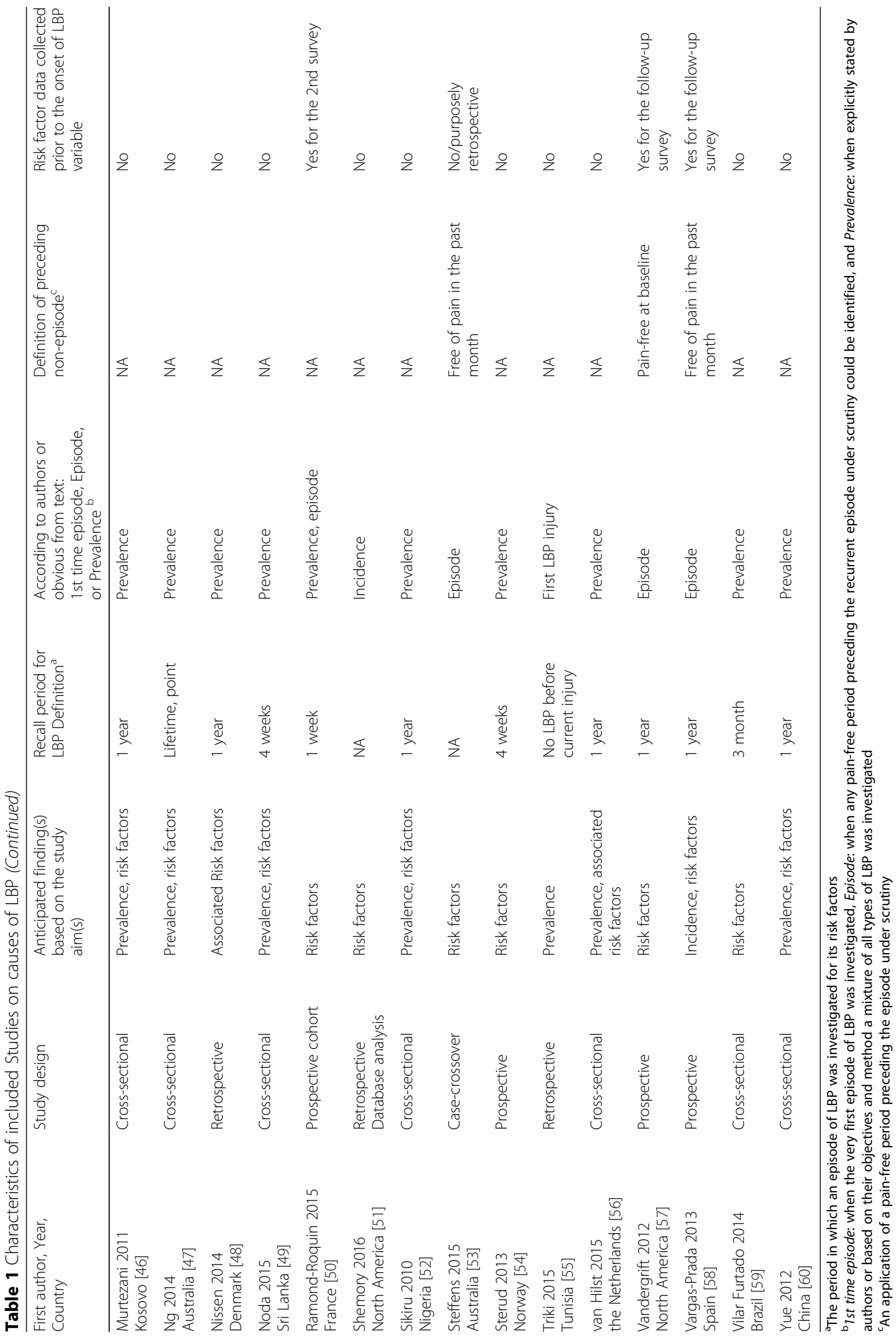


and case-crossover $(\mathrm{N}=1)$. Although some authors [35, $40,51]$ described their studies as retrospective, the process of data collection did not clearly indicate that.

To be able to scrutinise the approach researchers adopted towards the definition of the disease of LBP and its causes and risk factors, we tried to classify our included studies into three groups based on their objectives and methodology as follows:

1. Studies on the onset of the 'disease' of low back pain (first-time incident)

Five studies seemed to deal with the onset of the disease of LBP (i.e. its first occurrence or first episode ever) $[35,38,40,51,55]$. However, only three studies did attempt to capture subjects who had never had LBP before. Nevertheless, in two of these studies, the authors did not report on LBP per se but on the first-time diagnosis recorded in health care databases [35, 40]. Clearly, the first diagnosis of LBP does not necessarily signify the first episode ever of the pain. In the third one, the firsttime diagnosis of LBP injuries due to sporting activity was reported [55]. In this study participants with a history of LBP were excluded, however given the LBP variable was investigated as a result of a sports injury, the study would not necessarily capture all cases of LBP.

In a prospective study of incidence and onset of LBP, participants who had been free of pain for the past 3 months were included [38]. However, the preceding pain status and course of LBP were not taken into account.

The fifth study that purported to study the onset of LBP used data from a health care database that reported the incidence of LBP based on medical records [51]. Thus their patient cohort consisted of those who were diagnosed with LBP, which means we do not know whether this was the first episode ever of back pain.

2. Studies on the onset of new episodes of low back pain (recurring LBP)

Six studies (18\%) appeared to deal with risk factors for the onset of LBP episodes [30, 43, 44, 53, 57, 58].

Two of these studies defined the previous total absence of LBP as being free of pain in the past month $[53,58]$. The others, either did not identify the previous pain-free period $[30,43]$ or focused on being pain-free at baseline $[44,57]$.

The first study [53] employed a case-crossover study design to investigate triggers of a new episode of acute LBP. An acute episode of LBP was defined as a newonset of LBP of moderate intensity after at least one pain-free month.

The second study explored new episodes of LBP during the past month at both baseline and at a 12-month follow-up [58]. They defined the pain-free period to consist of 1 month prior to baseline, hence, making it possible to identify a new episode. The authors, however, give the impression that they were collecting data on incidence, i.e. information that also could include firsttime ever episodes (i.e. the disease of LBP).

The third and fourth reports [30, 43], using data from one single longitudinal cohort study, described two surveys on the participants aged 16 (first study) and 18 (follow-up study), studying risk factors for LBP during the past 6 months. Both studies reported the 6-month prevalence of LBP at both ages. Their definition of 'new LBP' at 18 was the absence of LBP for the 6 months before the first survey. Because adolescence is the time in life when the first-time episode of LBP commonly occurs [61], i.e. the very onset of the 'disease', many of the reported LBP cases would fit in this category. However, a subgroup would already have experienced one or several previous episodes and could, therefore, be classified as having a subsequent episode (had there been a clear definition of prior absence of pain) when surveyed at the age of 18 .

In the two prospective studies, in which participants without pain at baseline were included [44, 57], neither took a previous history of LBP into consideration. Therefore, it is not clear whether the pain appeared for the first time or was part of the course of the previous LBP.

3. Studies without a clear description of the type of LBP definition (possible mixture of first-time, recurring, and ongoing LBP)

In 22 studies, none of these two previously described possibilities (i.e. onset of either disease or an episode) were identified; hence they did, in fact, study the prevalence and not the incidence of LBP, whether ongoing or recurring. Nonetheless, some of the study participants, particularly if they were young, might have experienced their first episode ever. The recall periods for those prevalence studies ranged from 1 week to 1 year. With longer recall periods it is more likely that the LBP group would consist of a mixture of LBP definitions (i.e. firsttime, recurring, or ongoing).

\section{Reclassification of study type based on our interpretation of reports}

\section{Studies on the onset of the 'disease' of low back pain (first-time incident)}

None of the studies appeared truly to study the 'disease' of LBP. Among those five studies included in the category of first-time incident (onset of 'disease'), four articles $[35,38,40,51]$ have the propensity to include a 
mixture of first-time and recurrent episodes. The fifth study, did report first-time diagnosis of LBP injuries but due to sporting activity [55]. Although participants with a history of LBP were excluded, this study would therefore not necessarily capture all cases of LBP.

\section{Studies on the onset of new episodes of low back pain (recurring LBP)}

In addition, in 5 out of 6 studies [30, 43, 44, 57, 58] in the category of new episodes, the same ambiguity arose due to the unclear definition of LBP in relation to its previous pain-free period. Only one study provided a genuinely clear definition of an acute episode of LBP and was therefore able to provide causal information for the episodic LBP [53].

\section{Studies without a clear definition of type of LBP definition (possible mixture of first-time, recur- ring, and ongoing LBP)}

At first observation, 22 studies did not describe adequately their LBP definition and requirements. Nevertheless, a more thorough scrutiny of the articles initially placed in the first two categories had revealed that 4 of the first 5 and 5 of the second 6 , in fact, belonged to this third category. Thus, in all, 31 of our reviewed 33 studies were not able to study or differentiate the causes of the 'disease' or causes of episodes of LBP. Nevertheless, three studies would be able to study prediction of the first-time diagnosis of LBP $[35,40]$ with the possibility of including both first-time and recurring episodes, and one would be able to correctly identify factors predicting first-time LBP injury [55].

\section{Discussion}

According to this survey, many research reports relating to the causes of LBP fail to use a prospective study design and are not explicit on what aspect of LBP they are studying, i.e. the very onset (first episode) or subsequent episodes.

While some potential risk factors can be detected using a cross-sectional design, they clearly need to be present before the onset of LBP. Examples are sex and childhood socioeconomic circumstances, but for many potential risk factors a cross-sectional association merely means that there is a statistical association. A strong dose-response would be a good indication of a causal link [22], but the fundamental issue of temporality must first be established, in order to know that the link is causal. Therefore, in this review we chose to highlight the Bradford-Hill tenet of temporality because it is an absolute criterion for causality and is particularly relevant with diseases of slow development.
Because most prospective studies typically lacked a definition of the preceding 'non-episode', it was impossible to know if the purported causes related to the 'disease' or the episodes. De Vet et al. reported, in a previous publication, that researchers use different definitions of episodes/non-episodes and that in many studies there is no definition at all [62]. Her team recommended that there should be a consensus on what is meant by "episodes" and they proposed an episode of LBP should last at least $24 \mathrm{~h}$ and be preceded and followed by a period of at least 1 month without low back pain. The proposition was agreed in a modified Delphi study among a panel of international experts in LBP [59]. Some studies also investigated the application of the proposed definition in primary and secondary care patients $[12,60]$. Nevertheless, researchers seem to ignore or have not noticed this important recommendation.

As LBP often starts early in life, and is a recurring disorder, new cases are unlikely to occur later in life but are of course possible. Therefore, if it is unclear if study subjects, who were pain-free at baseline, were merely experiencing a pain-free 'non-episode' or if they had never previously had back pain at all. The younger they are, the more likely that it could be a first-time experience and the older they are, the more likely that they are experiencing yet another episode. This could perhaps be dealt with, if studies reported data distinctly for different age groups, or if study samples were representative of specific age groups.

In addition, there is a third group to contend with, namely those with persistent/chronic LBP. A recent study of the general population, using frequent text-message data collection on 50-year olds during 1 year, showed that there were three almost equally large groups: those who never or almost never have LBP, those who have it episodically, and those who almost always have it [63]. The last two groups may well have different sets of risk factors and must be separated during data collection.

In sum, the contemporary literature on the causality of LBP, with very few exceptions, is unable to bring any valuable answers to the questions of causality.

\section{Methodological considerations}

Some possible weaknesses of our review should be acknowledged. For instance, it is not certain that all relevant articles were retrieved. However, we were not looking for the answers to causes of LBP; instead, we were interested in researchers' recent approaches to causality, making it irrelevant to locate all relatively contemporary articles on this topic.

Another potential limitation was the search time limit. We did search for articles published from 2010. However, we wanted to include contemporary literature, which 
could provide us with an up-to-date general view on this topic.

There was no previously published and tested checklist suitable to our purposes. Perhaps another review team could have developed a different checklist with somewhat different results. However, our questions were simple and straightforward, so we consider this unlikely.

The extraction of data was done by two reviewers independently without any interest in the outcome. Since this topic is relatively new and literature is not clear on the definitions of types of LBP, information was often difficult to identify and extract due to lack of such definitions. Despite this, there was no occasion when a third reviewer needed to settle the disagreements, which indicates, at least, that the checklist was user-friendly. It is, of course, still possible that both reviewers misinterpreted some findings in the same direction.

\section{Conclusions}

In our study, we concentrated on a small but important detail, namely a clear statement of whether the disease of LBP or its episodes was studied. This aspect is important when establishing the temporality, i.e. the chronological order of events. The vast majority of the contemporary literature on the causality of LBP, captured in this review was unable to yield valid answers on both the LBP disease and the continued episodes of LBP.

This issue is important from a public health perspective but also for clinicians as, presently, it does not appear possible to advise patients on the causes of LBP.

Future research perspectives include the rigorous application of clear definitions of the baseline LBP status of participants and the use of standardised criteria for both absence and presence of LBP and a respect for the concept of temporality.

\section{Acknowledgements}

Not applicable.

\section{Funding}

Not applicable.

\section{Availability of data and materials}

Not applicable.

\section{Authors' contributions}

EA, BW and CLY were responsible for the study design. EA undertook the article search. EA and CLY performed the data analysis and interpretation and also developed the initial draft. BW and CLY were responsible for reviewing and redrafting the final manuscript. All contributed to the final version. All authors read and approved the final manuscript.

\section{Ethics approval and consent to participate}

Not applicable.

\section{Consent for publication}

Not applicable.

\section{Competing interests}

Associate Professor Bruce Walker AM is the Editor-in-Chief of Chiropractic \& Manual Therapies and Professor Charlotte Leboeuf-Yde is Senior Editorial Advisor to the same journal. Both were blinded to review and played no part in the editorial management of this submission.

\section{Publisher's Note}

Springer Nature remains neutral with regard to jurisdictional claims in published maps and institutional affiliations.

\section{Author details}

${ }^{1}$ School of Health Professions, Murdoch University, 90 South St, Murdoch, WA 6150, Australia. ${ }^{2}$ Institute for Regional Health Research, University of Southern Denmark, Odense, Denmark.

Received: 13 June 2017 Accepted: 20 December 2017

Published online: 09 January 2018

\section{References}

1. Murray $\mathrm{CJL}$, et al. Global, regional, and national disability-adjusted life years (DALYs) for 306 diseases and injuries and healthy life expectancy (HALE) for 188 countries, 1990-2013: quantifying the epidemiological transition. Lancet. 2015;386(10009):2145-91.

2. Gore $\mathrm{M}$, et al. The burden of chronic low back pain: clinical comorbidities, treatment patterns, and health care costs in usual care settings. Spine. 2012;37(11):E668-77.

3. van Tulder M, Koes B, Bombardier C. Low back pain. Best Pract Res Clin Rheumatol. 2002;16(5):761-75.

4. Krismer M, van Tulder M. Low back pain (non-specific). Best Pract Res Clin Rheumatol. 2007:21(1):77-91.

5. Lemeunier N, Leboeuf-Yde C, Gagey O. The natural course of low back pain: a systematic critical literature review. Chiropr Man Therap. 2012;20(1):33.

6. Manchikanti $\mathrm{L}$, et al. Epidemiology of low back pain in adults. Neuromodulation. 2014;17(Suppl 2):3-10.

7. Pengel LHM, et al. Acute low back pain: systematic review of its prognosis. BMJ. 2003;327(7410):323.

8. Itz CJ, et al. Clinical course of non-specific low back pain: a systematic review of prospective cohort studies set in primary care. Eur J Pain. 2013; 17(1):5-15.

9. Von Korff M. Acute low back pain improves rapidly, however recovery is not complete and recurrence is common. Aust J Physiother. 2004;50(1):58.

10. Hancock MJ, et al. Risk factors for a recurrence of low back pain. Spine J. 2015;15(11):2360-8.

11. Kongsted A, Leboeuf-Yde C. The Nordic back pain subpopulation program individual patterns of low back pain established by means of text messaging: a longitudinal pilot study. Chiropr Osteopat. 2009;17:11.

12. Leboeuf-Yde C, Jensen RK, Axen I. Absence of low back pain in patients followed weekly over one year with automated text messages. Chiropr Man Therap. 2012;20:9

13. Enthoven WTM, et al. Non-steroidal anti-inflammatory drugs for chronic low back pain. Cochrane Database Syst Rev. 2016;2:CD012087.

14. Furlan AD, et al. Acupuncture and dry-needling for low back pain. Cochrane Database Syst Rev. 2005;1:CD001351.

15. Hayden J, et al. Exercise therapy for treatment of non-specific low back pain. Cochrane Database Syst Rev. 2005;3:CD000335.

16. Rubinstein SM, et al. Spinal manipulative therapy for chronic low-back pain. Cochrane Database Syst Rev. 2011;2. Art. No.: CD008112. doi: https://doi.org/ 10.1002/14651858.CD008112.pub2.

17. Urquhart DM, et al. Antidepressants for non-specific low back pain. Cochrane Database Syst Rev. 2008;1:CD001703.

18. van Duijvenbode I, et al. Lumbar supports for prevention and treatment of low back pain. Cochrane Database Syst Rev. 2008;2:CD001823.

19. Wieland $L S$, et al. Yoga treatment for chronic non-specific low back pain. Cochrane Database Syst Rev. 2017;1:CD010671.

20. Yamato TP, et al. Pilates for low back pain. Cochrane Database Syst Rev. 2015;7.

21. Miquel P. A Dictionary of Epidemiology. New York: Oxford University Press. 2014. p. 251.

22. Hill AB. The environment and disease: association or causation? Proc $R$ Soc Med. 1965;58:295-300.

23. Yao W, et al. Risk factors for nonspecific low-back pain in Chinese adolescents: a case-control study. Pain Med. 2012;13(5):658-64. 
24. Xu X, et al. Analysis of risk factors of nonspecific low back pain in a community population: a case-control study. Nan fang yi ke da xue xue bao. J Southern Med Univ. 2014;34(12):1794-8.

25. Oliveira VC, et al. Risk factors for low back pain: insights from a novel casecontrol twin study. Spine J. 2015;15(1):50-7.

26. Li JY, et al. Risk factors of low back pain among the Chinese occupational population: a case-control study. Biomed Environ Sci. 2012;25(4):421-9.

27. Steffens $D$, et al. Clinicians' views on factors that trigger a sudden onset of low back pain. Eur Spine J. 2014;23(3):512-9.

28. Aggarwal N, Anand T, Kishore J, Ingle GK. Low back pain and associated risk factors among undergraduate students of a medical college in Delhi. Educ Health (Abingdon). 2013;26(2):103-8.

29. Alperovitch-Najenson D, Santo Y, Masharawi Y, Katz-Leurer M, Ushvaev D, Kalichman L. Low back pain among professional bus drivers: ergonomic and occupational-psychosocial risk factors. Isr Medi Assoc J. 2010;12(1):26-31.

30. Auvinen JP, Tammelin TH, Taimela SP, Zitting PJ, Järvelin MR, Taanila AM, Karppinen II. Is insufficient quantity and quality of sleep a risk factor for neck, shoulder and low back pain? A longitudinal study among adolescents. Eur Spine J. 2010;19(4):641-9.

31. Capkin E, Karkucak M, Cakirbay H, Topbas M, Karaca A, Köse MM, Gökmen F. The prevalence and risk factors of low back pain in the eastern Black Sea region of Turkey. J Back Musculoskelet Rehabil. 2015;28(4):783-7.

32. Cho NH, Jung YO, Lim SH, Chung CK, Kim HA. The prevalence and risk factors of low back pain in rural community residents of Korea. Spine. 2012:37(24):2001-10

33. Coenen P, Kingma I, Boot CR, Twisk JW, Bongers PM, Van Dieën JH. Cumulative low back load at work as a risk factor of low back pain: a prospective cohort study. J Occup Rehabil. 2013;23(1):11-8.

34. Erick PN, Smith DR. Low back pain among school teachers in Botswana, prevalence and risk factors. BMC Musculoskelet Disord. 2014;15:359.

35. Ernat J, Knox J, Orchowski J, Owens B. Incidence and risk factors for acute low back pain in active duty infantry. Mil Med. 2012;177(11):1348-51.

36. Gaowgzeh RA, Chevidikunnan MF, Al Saif A, El-Gendy S, Karrouf G, Al Senany S. Prevalence of and risk factors for low back pain among dentists. J Phys Ther Sci. 2015;27(9):2803-6.

37. Jia N, Li T, Hu S, Zhu X, Sun K, Yi L, Zhang Q, Luo G, Li Y, Zhang X, Gu Y, Wang Z. Prevalence and its risk factors for low back pain among operation and maintenance personnel in wind farms. BMC Musculoskelet Disord. 2016;17:314

38. Kanchanomai $S$, Janwantanakul P, Pensri P, Jiamjarasrangsi W. A prospective study of incidence and risk factors for the onset and persistence of low back pain in Thai university students. Asia Pac J Public Health. 2015;27(2):NP106-15.

39. Katsavouni F, Bebetsos E, Antoniou P, Malliou P, Beneka A. Work-related risk factors for low back pain in firefighters. Is exercise helpful? Sport Sciences Health. 2014;10(1):17-22.

40. Orchowski JR KJB, Scher DL, Owens BD, Burks R, Belmont PJ Jr. Occupational driving as a risk factor for low back pain in active-duty military service members. Spine J. 2014;14(4):592-7.

41. Lin JD, Lin LP, Su SF, Hsu SW, Loh CH, Wu JL, Chu CM. Personal and workplace factors for the risk of low back pain among institutional caregivers of people with intellectual, autistic or multiple disabilities. Res Autism Spectrum Disord. 2014;8(5):509-17.

42. Lin PH, Tsai YA, Chen WC, Huang SF. Prevalence, characteristics, and workrelated risk factors of low back pain among hospital nurses in taiwan: a cross-sectional survey. Int J Occup Med Environ Health. 2012;25(1):41-50.

43. Mikkonen P, Heikkala E, Paananen M, Remes J, Taimela S, Auvinen J, Karppinen J. Accumulation of psychosocial and lifestyle factors and risk of low back pain in adolescence: a cohort study. Eur Spine J. 2016;25(2):635-42.

44. Mitchell T, O'Sullivan PB, Burnett A, Straker L, Smith A, Thornton J, Rudd CJ. Identification of modifiable personal factors that predict new-onset low back pain: a prospective study of female nursing students. Clin J Pain. 2010;26(4):275-83

45. Mohseni-Bandpei MA, Ahmad-Shirvani M, Golbabaei N, Behtash H, Shahinfar Z, Fernández-De-Las-Peñas C. Prevalence and risk factors associated with low back pain in Iranian surgeons. J Manip Physiol Ther. 2011;34(6):362-70.

46. Murtezani A, Ibraimi Z, Sllamniku S, Osmani T, Sherifi S, et al. Folia Med. 2011;53(3):68-74

47. Ng L, Perich D, Burnett A, Campbell A, O'Sullivan P. Self-reported prevalence, pain intensity and risk factors of low back pain in adolescent rowers. J Sci Med Sport. 2014;17(3):266-70.
48. Nissen LR, Marott JL, Gyntelberg F, Guldager B. Deployment-related risk factors of low back pain: a study among danish soldiers deployed to Iraq Mil Med. 2014;179(4):451-8.

49. Noda M, Malhotra R, DeSilva V, Sapukotana P, DeSilva A, Kirkorowicz J, Allen J, Østbye T. Occupational risk factors for low back pain among drivers of three-wheelers in Sri Lanka. Int J Occup Environ Health. 2015;21(3):216-22.

50. Ramond-Roquin A, Bodin J, Serazin C, Parot-Schinkel E, Ha C, Richard I, Petit Le Manach A, Fouquet N, Roquelaure Y. Biomechanical constraints remain major risk factors for low back pain. Results from a prospective cohort study in French male employees. Spine J. 2015;15(4):559-69.

51. Shemory ST, Pfefferle KJ, Gradisar IM. Modifiable risk factors in patients with low back pain. Orthopedics. 2016;39(3):e413-6.

52. Sikiru $L$, Hanifa S. Prevalence and risk factors of low back pain among nurses in a typical Nigerian hospital. Afr Health Sci. 2010;10(1):26-30.

53. Steffens D, Ferreira ML, Latimer J, Ferreira PH, Koes BW, Blyth F, Li Q, Maher CG. What triggers an episode of acute low back pain? A case-crossover study. Arthritis Care Res. 2015;67(3):403-10.

54. Sterud T, Tynes T. Work-related psychosocial and mechanical risk factors for low back pain: a 3-year follow-up study of the general working population in Norway. Occup Environ Med. 2013;70(5):296-302.

55. Triki M, Koubaa A, Masmoudi L, Fellmann N, Tabka Z. Prevalence and risk factors of low back pain among undergraduate students of a sports and physical education institute in Tunisia. Libyan J Med. 2015;10:26802.

56. Van Hilst J, Hilgersom NF, Kuilman MC, Kuijer PP, Frings-Dresen MH. Low back pain in young elite field hockey players, football players and speed skaters: prevalence and risk factors. J Back Musculoskelet Rehabil. 2015;28(1):67-73.

57. Vandergrift JL, Gold JE, Hanlon A, Punnett L. Physical and psychosocial ergonomic risk factors for low back pain in automobile manufacturing workers. Occup Environ Med. 2012;69(1):29-34.

58. Vargas-Prada S, Serra C, Martínez JM, Ntani G, Delclos GL, Palmer KT, Coggon D, Benavides FG. Psychological and culturally-influenced risk factors for the incidence and persistence of low back pain and associated disability in Spanish workers: findings from the CUPID study. Occup Environ Med. 2013;70(1):57-62.

59. Vilar Furtado RN, Ribeiro LH, Abdo BA, Descio FJ, Martucci Junior CE, Serruya DC. Nonspecific low back pain in young adults: associated risk factors. Rev Bras Reumatol. 2014:54(5):371-7.

60. Yue P, Liu F, Li L. Neck/shoulder pain and low back pain among school teachers in China, prevalence and risk factors. BMC Public Health. 2012;12:789.

61. Jones $\mathrm{G}$, Macfarlane $\mathrm{G}$. Epidemiology of low back pain in children and adolescents. Arch Dis Child. 2005:90(3):312-6.

62. de Vet $\mathrm{HC}$, et al. Episodes of low back pain: a proposal for uniform definitions to be used in research. Spine (Phila Pa 1976). 2002;27(21):2409-16.

63. Leboeuf-Yde $C$, et al. Evidence-based classification of low back pain in the general population: one-year data collected with SMS track. Chiropr Man Therap. 2013;21:30.

\section{Submit your next manuscript to BioMed Central and we will help you at every step:}

- We accept pre-submission inquiries

- Our selector tool helps you to find the most relevant journal

- We provide round the clock customer support

- Convenient online submission

- Thorough peer review

- Inclusion in PubMed and all major indexing services

- Maximum visibility for your research

Submit your manuscript at www.biomedcentral.com/submit
) Biomed Central 